\title{
SOCIAL REHABILITATION
}

$\mathrm{O}^{\mathrm{N}}$ $\mathrm{NE}$ of the consequences of the social disturbance and distress which have accompanied the widespread destruction of private property in the indiscriminate bombing attacks on London and other areas has been the realization that problems of social reconstruction have to be faced now and cannot be deferred until the end of hostilities is in sight. Whatever evacuation or shelter policy may now be adopted must be part of a long-term policy, keeping in mind the possibility of a long war, and designed to conserve morale and resources as effectively as possible. Short-sighted temporizing and timid palliatives are a public danger, and can no more be tolerated than the administrative incompetency from which they spring.

Recent events have made it plain beyond question that planning for social reconstruction must be undertaken in the midst of the War and as part of its effort with a vigour, a vision and a courage worthy alike of the gallant few on whom the main brunt of defence has fallen, the heroism of the civil defence services and the patient fortitude of those who have seen their homes and families shattered and scattered. The relief of distress in the stricken areas, evacuation of nonessential classes from the more dangerous districts no less than the restoration of public services which have been interrupted or dislocated, and other measures of social rehabilitation are tasks calling for immediate attention. None the less they should be handled not merely in respect of immediate and urgent needs but also in relation to the long-range problems of social rehabilitation and reconstruction which will confront us after the War.

The relief of distress and social reconstruction in the heavily bombed areas represent only one aspect of the question of social rehabilitation. The nation is equally committed to the care of its fighting men; to see that when the War is over they may secure their places in civil life or find new places in which their energies can be employed. The care of the disabled soldier and of those suffering from cardiac, nervous and other afflictions is a particular aspect of such rehabilitation, and as to the value of this work the experience of the War of 1914-18 leaves no room for doubt. Equally that experience warns us of the danger of allowing what promised to become the foundation of a great national effort to dwindle to meagre or insignificant proportions. If justice is to be done to our fighting men, our gratitude to them to find adequate expression and even our pledgess honoured, now is the time to look forward, to plan on an adequate scale and take such immediate steps as will prevent us again missing our goal.

If this is one of the main reasons for giving attention to such problems of social reconstruction at this hour, to ensure that the lines of an adequate policy and necessary measures and resources are available when the need for action arrives, so as to avoid the confusion and mistakes that are inevitable if we wait until such problems urgently arise, there is another equally as important. Our immediate problems and needs are related in a remarkable way to our long-range problems in this field, and attention to the latter requirements in dealing with the former may well assist to conserve our resources as well as facilitate reconstruction after the War. What is even more important is the contribution which such vision and long-range planning may make to public morale.

It is impossible to take a cross-section of opinion in Great Britain to-day without realizing the extent to which social reconstruction looms in the minds and thoughts of almost all sections of the community. The realization that the struggle is fundamentally between two entirely different social orders, between one in which the State is supreme and the individual is without rights and exists merely to serve the State, and one in which the State exists to serve those needs of individuals which must be met collectively in an ordered society, is widespread. Many indeed are coming to look for a new social order from which the grosser inequalities of wealth and opportunity have been eliminated and in which a finer tradition of public service is shared by all. If into such planning and reconstruction as are demanded now we could get something of this spirit and vision we might well give to those on whom have fallen the severest blows and heaviest strain just that inspiration and hope which count for most in maintaining morale and endurance under the War's sternest trials. 
Such a possibility cannot be dismissed as impracticable or Utopian. We are apt, as Prof. J. H. Jones has pointed out, to exaggerate the real and enduring suffering caused by war and to assume the inevitability of poverty for long years after the War has come to an end. Such poverty is not inevitable if the resources of Nature, of technical skill and energy which will remain, with most of our capital resources are used with imagination and effectively organized. We have already indicated how reconstruction in the stricken areas, whether undertaken now or after the War, might be carried out in accordance with an adequate national plan and not marred again by limitations imposed by departmentalism, parochialism or vested interests. Similarly in the field of rehabilitation of the fighting men, as Dame Agnes Hunt has pointed out, there is real need for co-ordination in view of the many organizations concerned. Coordination, if it is to be effective, must stand above medical and vocational treatment and reemployment, with its corollary of a scale of pensions. Some rearrangement of existing responsibilities is necessary.

If the Ministry of Health, for example, acting through its Emergency Medical Service, assumed some of the duties now being discharged by the Ministry of Pensions and by the Board of Education, the ideal of a National Medical Service would be appreciably nearer realization. The Ministry of Health would thus become the sole authority of State on medical and surgical questions and would be in a position to lay down broad principles of procedure for the guidance of the secular ministries. Moreover, the work it is at present doing for disabled soldiers would thus become the basis not only of re-education but also of reemployment, and a beginning would have been made with the task of dealing with persons unable to perform heavy work or to work continuously

The importance of this to industry is obvious, and equally its special value at the present time when our War effort demands the maximum utilization of man- and woman-power. The development of a National Medical Service in this way might well enable us to restore to industry without danger, not only many of the victims of tuberculosis as the work of the Papworth Village Settlement has shown, but also those of some cardiac and nervous and other chronic diseases if adequate steps were taken to secure their welfare. Even if such additions to our industrial resources were not effected in this way during the present
War, we have here yet another striking example of the way in which far-sighted, long-range action is of benefit to our immediate purposes.

What must be kept particularly in mind is the importance of undertaking the requisite study of such problems now as a prelude to planning. For this reason alone the publication of Mr. D. M. Goodfellow's study of Tyneside (see p. 485 of this issue) is opportune. The social and industrial disturbances of war inevitably leave a legacy of problems. Areas of intense industrial activity in war-time are practically depressed areas in peacetime. Migration, whether of workers into centres of industry to increase production, or of workers and factories to less vulnerable and non-industrial parts of the country, are apt to involve distortion of development, lack of balance in productive capacity and of variety of occupation. The consequent problems to which attention in war-time is imperative even on the bare ground of production become even more acute when redistribution has to be faced after the War.

The Royal Commission on the Geographical Distribution of the Industrial Population in its recent report frankly faced a number of the problems of industrial dislocation at the end of the War, which indeed its recommendations are designed to mitigate. Mr. Goodfellow's report is concerned much more with social and welfare conditions, but equally emphatically he emphasizes the need for preparing plans for the transition well in advance and ready for application. Like the Barlow Commission, he stresses the need for coordination and for relating the measures of the Government, the local authorities and industry.

Social preparations must be planned and readjustments can no longer be left to chance. On that the investigations of $\mathrm{Mr}$. Goodfellow and the members of his tutorial class organized by the Workers' Educational Association leave no room for doubt. They also trace the lowered vitality on Tyneside to-day back to a false prosperity which reached its apex during 1914-18 and weakened resistance in the long depression which followed. The scarcity of essential foods, and overcrowding and deficiencies in cleanliness and the normal care of children, partly through the absence of mothers working in the factories, played their part, and it needs little imagination to realize how serious a situation might well arise during the present War, let alone after it, even leaving out of account the disturbance and dislocation which heavy air attack may cause. 
To some of these dangers the Government are already clearly alive, but one of the most significant features of the report is the fresh support it brings to the recommendations of the Royal Commission of Local Government in the Tyneside area. This acute piece of analysis emphasizes the erratic character of the Tyneside social services. They in no way correspond to the needs of the whole area. In many important services only Newcastle-uponTyne reaches the national standard. In others, some Tyneside towns make special efforts and rise far above that standard, while others fall far below it.

This inordinate disparity in the health and other social services on Tyneside is not always determined by poverty. Some of the poorest Tyneside towns make the best efforts to improve the conditions of their citizens, but do so only by taxing these citizens and so intensifying poverty. It is for this reason that Mr. Goodfellow sees danger in the formation of a region consisting of industrial Tyneside and Northumberland County as likely to lead to an over-emphasis of agricultural interests and continued disparities of social services. $\mathrm{He}$ recommends that Durham should be included from the first, if only because of Durham's excellent achievements in the development of social services, which indicate an attitude likely to be beneficial if not essential to the development of Tvneside.

Mr. Goodfellow suggests, however, that the division of local services into two types, regional and local, requires more consideration. In his view a regional authority for all purposes, controlling all services and strengthened by ownership of public utilities, would stand the best chance, without any danger of friction from minor authorities within its own boundary, of satisfying the conditions of the reports of the Barlow Commission. Such a regional authority would be able to speak with one voice as regards the industrial development and planning of the north-eastern region, its equitable treatment by the national exchequer, and the uniform development of its social services on the lines required by both industrial and agricultural districts. It might well also encourage the local development of the potential resources in leadership.

The value of this survey at the present time is unmistakable. It is a timely reminder that social welfare, the quality of the health and social services, cannot be let down at any time, even amid the desperate need of war, without the exaction of a heavy penalty later. Industrial and social policy must be brought together in a comprehensive welfare policy. Scientific workers will recognize Mr. Goodfellow's investigations as a sample of what might well be attempted elsewhere as a prelude to planning for social reconstruction. They should be grateful also for the stimulus it gives to the scientific consideration of the larger issues involved in regionalism. War-time developments have already opened up wider possibilities which might be utilized in the development of our plans for reconstruction after the War.

These possibilities cannot, even in the stress of war, be left purely to chance. Even now we must turn all available scientific energies to studying the causes of our difficulties. We cannot clearly prophesy to-day what form the society of the future will take, but as Mannheim has pointed out we need a new kind of foresight, a new technique for managing conflicts, together with a psychology, morality and plan of action in many ways completely different from those which have obtained in the past. It is only by re-making man himself that the reconstruction of society is possible. A conscious attack on the sources of maladjustment in the social order in this way, based on a thorough knowledge of the whole mechanism of society and the way in which it works, an attack on the strategic points and not the treatment of symptoms, might well yield results far beyond expectation and make some of the sacrifices of the War well worth while.

Scientific workers carry an inescapable responsibility for helping their fellow citizens to see and face these possibilities and responsibilities. They might well lend their support to such a central body as the Reconstruction Commission advocated by Prof. Jones, or sectional groups concerned with particular problems like the Architects National Council, which are attempting to study, collate and co-ordinate the changes that are occurring and the problems which emerge. Certain it is that if we are to see the health of the nation adequately safeguarded during and after the War and those whose lives have been disrupted, whether physically, mentally or spiritually by the impact of War, rehabilitated and established in a new social order, the planning and action must be based on fearless scientific investigation and courageous and farsighted administration, untrammelled by departmentalism or prejudice. 